\title{
DOENÇAS PSICOLÓGICAS DENTRO DAS RELAÇÕES DE TRABALHO: UM PARÂMETRO SOBRE AS DOENÇAS QUE MAIS AFASTAM AS PESSOAS DO TRABALHO.
}

\author{
Dyellma Suellem Garcia Cardoso; Francislaine de Almeida Coimbra Strasser; \\ Universidade do Oeste Paulista - UNOESTE, Curso de Direito, Presidente Prudente, SP. E-mail: \\ dyellmacardoso2007@hotmail.com
}

\section{RESUMO}

O presente artigo tem por objetivo demonstrar a importância em se debater as doenças psicológicas relacionadas ao cotidiano frenético dentro das empresas e que, como consequência, resulta em afastamentos e ajuizamentos de reclamações trabalhistas.

Importante também no sentido jurídico de se preservar os direitos fundamentais do indivíduo, bem como a dignidade do mesmo, visando a proporcionar uma conscientização de todas as partes nas relações de trabalho, para desenvolver a valorização ao ambiente de trabalho com qualidade de vida. Para tanto, utilizou-se o método hipotético-dedutivo, realizado através de pesquisa bibliográfica, com a utilização de doutrina, artigos eletrônicos e textos normativos, infraconstitucional e constitucional. A conclusão a que se chegou foi da necessidade da conscientização dos empregadores na gestão das atividades laborativas no sentido de se preservar a saúde dos trabalhadores "mergulhados" na era do capitalismo, em que se impera a lógica do resultado.

Palavras chaves: Doenças psicológicas; Direito do trabalho; Dignidade; Relações de Trabalho; Ambiente de trabalho seguro.

\section{PSYCHOLOGICAL DISEASES WITHIN THE WORK RELATIONS: A PARAMETER ON THE DISEASES THAT MOST AFFECT WORK PEOPLE.}

\begin{abstract}
The purpose of this article is to demonstrate the importance of discussing psychological illnesses related to the frenetic daily life within companies and, as a consequence, results in dismissals and claims of labor claims. Also important in the legal sense of preserving the fundamental rights of the individual, as well as the dignity of the same, aiming to provide an awareness of all parties in the labor relations, to develop the valuation of the work environment with quality of life. For that, the hypothetical-deductive method was used, through bibliographical research, using doctrine, electronic articles and normative, infraconstitutional and constitutional texts. The conclusion reached was the need to raise the awareness of employers in the management of labor activities in order to preserve the health of the workers "immersed" in the era of capitalism, where the logic of the result prevails.
\end{abstract}

Keywords: Psychological diseases; Labor law; Dignity; Work relationships; Safe working environment. 


\section{INTRODUÇÃO}

O meio ambiente do trabalho engloba o ambiente como um todo, que por sua vez integra o rol dos Direitos Humanos Fundamentais, inclusive porque objetiva o respeito à dignidade da pessoa humana, valor supremo que revela o caráter único e insubstituível de cada ser humano, figurando, ainda como verdadeiro fundamento da República Federativa do Brasil, conforme artigo 10, III, da Constituição Federal de 1988.

Ademais, o artigo 225 da Lei Maior disciplina o meio ambiente como direito fundamental, sendo direito de todos, conservá-lo de forma ecologicamente equilibrada.

Portanto, o ambiente de trabalho deve ser sadio de um modo geral, tanto no aspecto físico proporcionando condições adequadas de trabalho, quanto no psíquico, em que todas as diferenças são respeitadas, de forma que o assédio moral não seja uma prática, não haja discriminação, enfim, num ambiente psicologicamente adequado.

Eis a importância do tema, pois para que um contrato de trabalho cumpra a sua função social deverá proporcionar uma relação de emprego decente, que nada mais é que preservar a dignidade do trabalhador pela manutenção de um meio ambiente equilibrado e saudável, o que somente poderá ser alcançado se houver uma contribuição efetiva de todos os envolvidos no processo, como empregador, empregado e Estado.

\section{METODOLOGIA}

O presente estudo seguirá o método dialético-dedutivo, com emprego de pesquisa à legislação e doutrina acerca da matéria objeto da investigação, além de artigos eletrônicos e textos normativos, infraconstitucional e constitucional.

\section{MEIO AMBIENTE DO TRABALHO}

A Lei no 6.938/81 em seu artigo 3으, inciso I define meio ambiente como: "conjunto de condições, leis, influências e interações de ordem física, química e biológica, que permite, abriga e rege a vida em todas as suas formas".

Assim, o meio ambiente do trabalho está englobado no ambiente geral, de forma que existe uma relação que é: não se pode conseguir alcançar qualidade de vida sem um meio ambiente equilibrado e nem se pode atingir meio ambiente equilibrado e sustentável, ignorando o meio ambiente do trabalho.

Nessa perspectiva, a Magna Carta estabeleceu em seu artigo. 7으, inciso XXII como sendo um direito do trabalhador a "redução dos riscos inerentes ao trabalho, por meio de normas de saúde, higiene e segurança", no artigo 170, VI que "a ordem econômica deve observar princípio da defesa do meio ambiente", e por fim em seu artigo 225 que "todos tem direito ao meio ambiente ecologicamente equilibrado, uso comum do povo e essencial à sadia qualidade de vida...." (BRASIL, 1988).

Dessa forma, além de ser um direito do trabalhador a manutenção do ambiente de trabalho saudável, é mais do que nunca um dever do empregador.

Ressalta-se que o direito a vida ganha um sentido mais profundo, já que vai além da ideia de sobrevivência, englobando vida com qualidade, na interação do homem com a natureza, produção e, sobretudo ao trabalho.

Por conseguinte, é manifesto que o direito ao meio ambiente equilibrado é sim, direito fundamental, materialmente considerado, uma vez que está intimamente ligado ao direito à vida.

É no ambiente do trabalho que o homem produz para garantir seu sustento, é onde desenvolve capacidade física e mental, de forma que é muito importante a manutenção do meio ambiente do trabalho equilibrado, pois exerce uma influência direta sobre o comportamento desse trabalhador, podendo até interferir em sua família. 
Dessa forma, o direito ao meio ambiente do trabalho sadio e equilibrado, como aspecto do meio ambiente geral proporciona uma vida com qualidade e dignidade ao trabalhador.

\section{AS DOENÇAS PSICOLÓGICAS DESENCADEADAS NO TRABALHO}

No plano real, todavia, o primado da "sadia qualidade de vida" (art. 225, caput, CF/88), nem sempre é observado.

O que ocorre é que aquele que contrata o trabalho tem o dever de preservar a integridade do trabalhador, que seria zelar pelo seu bem estar físico, mental e social. Todavia, as empresas estipulam metas e promoções baseadas em resultados, sob o pretexto de compensações pela mão de obra para intensificar as produções em massa, o que favorece o surgimento de doenças psicológicas relacionadas com a forma de gestão incorreta de pessoas. As doenças listadas como as mais recorrentes e que motivam o afastamento do trabalho são:

Depressão: é um distúrbio afetivo que acompanha a humanidade ao longo de sua história. Pessoas que sofrem com distúrbios de depressão apresentam uma tristeza profunda, perda de interesse generalizado, falta de ânimo, de apetite, ausência de prazer e oscilações de humor que podem culminar em pensamentos suicidas. (SOCIEDADE BRASILEIRA DE PSICOLOGIA, 2018).

É importante ressaltar que a depressão é diferente de tristeza.

A tristeza geralmente é desencadeada por alguma situação do cotidiano onde o indivíduo sofre por não ter tido tempo para assimilar o que ocorreu, e este sentimento dura no máximo 15 dias. 0 mesmo não acontece com a depressão, pois essa não tem prazo para acabar. Passa por estágios e pode se agravar se não for tratada. (SANTOS, 2018)

Além da depressão, segundo Vanessa dos Santos (2018) cite-se a doença Síndrome do Pânico, "que é um tipo de transtorno de ansiedade no qual ocorrem crises inesperadas de desespero e medo intenso de que algo ruim aconteça, mesmo que não haja motivo algum para isso ou sinais de perigo iminente".

Pessoas com esse transtorno sofrem com crises agudas de medo recorrente. Sendo totalmente imprevisível. Geralmente essas pessoas ficam preocupadas pensando na próxima crise que terão.

Ademais, a ansiedade é um momento em que a sensação de angústia e insegurança aumenta de forma a deixar o indivíduo descontrolado com a sensação de que alguma desgraça deverá acontecer com ele ou com as pessoas importantes para ele.

Quando o indivíduo percebe que está tendo uma crise, a melhor forma de tentar remediar é organizar a mente tentando não pensar no que pode acontecer de pior.

E, por fim a síndrome de Burnout:

é uma consequência do acúmulo excessivo de estresse em trabalhadores que têm uma profissão muito competitiva ou com muita responsabilidade, tornando o dia de trabalho em um sacrifício que envolve nervosismo, sofrimento psicológico e problemas físicos, como dor de barriga, cansaço excessivo ou tonturas, por exemplo. (SANTOS, 2018)

A síndrome é que mais se encaixa no contexto profissional, pois a pessoa que sofre com a doença não sabe lidar com a falta de valorização do próprio trabalho pelos superiores. Sendo, portanto, uma síndrome que nasce no ambiente de trabalho por ter o fator da carga horária de trabalho.

\section{O ASSÉDIO MORAL COMO FATOR PREPONDERANTE DE AGRESSÃO}

Dentre as modalidades de agressão que ocorrem no ambiente de trabalho e que causam transtornos, tanto na parte física, como na psique no trabalhador, destaca-se o assédio moral.

$O$ assédio moral é conceituado como: 
a ação ou omissão de uma pessoa, ou de um grupo de pessoas dirigida a um indivíduo ou grupo de indivíduos, utilizando de violência psicológica, de forma reiterada durante um longo período de tempo, com o intuito de destruir os círculos de relacionamento da vítima, bem como sua reputação, incomodá-lo quando estiver exercendo suas atividades, até que por fim, o indivíduo peça demissão. (BARROS, 2011, p.743)

Não obstante dentre os poderes do empregador estar inserido o de fiscalização, gerência e organização, não justifica a utilização de métodos que exijam uma produtividade que extrapola os limites da normalidade, superiores a sua força, alheios o contrato com rigor excessivo. Referida conduta é tida como abusiva pela doutrina. "Por abusividade de conduta intencional, entende-se como sendo aquela que extrapola os poderes da chefia, visando, exclusivamente, denegrir o trabalhador na sua esfera pessoal". (PANPLONA FILHO; BARROS, 2013, p. 585).

Entretanto, a conduta de destruir a esfera pessoal do trabalhador, impondo-lhe metas acima da capacidade de resolução de um homem médio, tem sido frequente nos meios ambientes de trabalho.

O que ocorre é que o empregador que é responsável por garantir aos seus empregados um meio ambiente do trabalho saudável, com o devido respeito a sua dignidade e ao seu bem estar físico, mental e social acaba por expor esses empregados ou um empregado a reiteradas situações constrangedoras, humilhantes e abusivas, fora dos limites normais do poder diretivo, aviltando com isso a dignidade da pessoa humana e ao adoecimento de natureza ocupacional.

A pessoa tomada como alvo percebe a má intenção de que é objeto, ela é ferida em seu amor próprio, sente-se atingida em sua dignidade e sente a perda súbita da autoconfiança.

Na realidade, é uma relação de dominante- dominado na qual aquele que comanda o jogo procura submeter o outro até que ele perca a identidade e fica cada vez mais difícil se defender, já que a vítima a é isolada do grupo, pois desta forma fica mais fácil fragilizá-la.

De acordo com a Organização Mundial da Saúde:

Considera-se violência no trabalho situações em que o trabalhador é agredido física, psicológica ou moralmente em circunstâncias relacionadas ao trabalho, implicando em risco para a sua segurança, bem-estar ou saúde. A OMS reconhece que a violência no trabalho afeta milhões de trabalhadores no mundo todo, tornando-se cada vez mais uma questão de direitos humanos e afetando de forma relevante a eficiência e o sucesso das organizações. (ROMANA, 2015).

Comprovado o assédio moral, a vítima poderá pleitear do empregador indenização por danos morais. $O$ valor a ser arbitrado pelo juiz considera a finalidade compensatória para a vítima e punitiva para o empregador. Além disso, deve considerar a intensidade e duração do assédio, a condição econômica do empregador, a conduta do assediador, os efeitos danosos causados, dentre outros.

Se o assédio provocar adoecimento com afastamento do trabalho, como é muito frequente, caberá também indenização por danos materiais em razão da incapacidade permanente da vítima.

\section{CONCLUSÃO}

O presente artigo objetivou refletir sobre o que tem ocorrido em nossa sociedade de forma alarmante. É imprescindível que as organizações empresarias modifiquem seu modo de gerir suas empresas, bem como importar-se com a qualidade de vida proporcionada a seus empregados. Não só pelo aspecto psicológico, mas por esta modificação trazer resultados positivos para a própria empresa de modo a reduzir possíveis processos e afastamentos.

Essencial apontar que é importante tratar da correlação entre as doenças psicológicas nascidas em um meio ambiente de trabalho, pois o individuo torna-se escravo desses transtornos, 
o que nenhum valor pecuniário é capaz de indenizar o trauma vivido por essas pessoas, e não há como retroagir em nenhum de seus aspectos.

Dessa forma, faz-se mister a conscientização das empresas, na gestão primando pela qualidade no meio ambiente de trabalho.

\section{REFERÊNCIAS}

BARROS, Alice Monteiro de. Curso de Direito do Trabalho. 7. Ed. São Paulo: LTr, 2011.

BRASIL. Constituição (1998). Constituição da República Federativa do Brasil. Brasília: Senado Federal, 1988.

HERNANDES MARTÍNEZ, Maria del Pilar. Constitución y derechos fundamentales. Disponível em: <http://www.juriicas.unam.mx/publica/rev/boletin/cont/84/art5.htm17 mar.2010. Acesso: 05 ago.de 2018

PAMPLONA FILHO, Rodolfo Mário Veiga; BARROS, Renato da Costa Lino de Goes. A distinção do assédio moral de figuras afins. Brasília, v. 14 n. 104. Out. 2012/Jan. 2013.

ROMANA, Lívia Gallerani. Transtornos mentais relacionados ao trabalho. Disponível em: <https://www.rhportal.com.br/artigos-rh/transtonrosmentaisrelaiconadosaotrabalho>Acesso: 01 julho. de 2018.

ROSENVALD, Nelson. Dignidade humana e boa-fé no Código Civil. São Paulo: Saraiva. 2005.

SANTOS, Vanessa dos. Doenças psicológicas. Disponível em: <https://biologianet.uol.com.br/doencas/doencas-psicologicas.htm>Acesso: 05 julho. de 2018 .

SOCIEDADE BRASILEIRA DE PSICOLOGIA. Disponível em: <http://www.sbponline.org.br/>Acesso em: 05 ago.de2018. 